\title{
O DEBATE ENTRE ORIGINALISMO E O CONSTITUCIONALISMO DEMOCRÁTICO: ASPECTOS ATUAIS DA TEORIA DA INTERPRETACÃO CONSTITUCIONAL NORTE- AMERICANA
}

THE DEBATE BETWEEN ORIGINALISM AND DEMOCRATIC CONSTITUTIONALISM: CURRENT ASPECTS OF THE NORTH AMERICAN THEORY OF CONSTITUTIONAL INTERPRETATION

EL DEBATE ENTRE EL ORIGINALISMO Y EL CONSTITUCIONALISMO DEMOCRÁTICO: ASPECTOS ACTUALES DE LA TEORÍA DE LA INTERPRETACIÓN CONSTITUCIONAL NORTEAMERICANA

José Ribas Vieira ${ }^{1}$

Deo Campos Dutra²

\section{RESUMO}

O presente texto tem como objetivo apresentar a doutrina de interpretação constitucional oriunda da Escola de Yale. Tal doutrina fundamenta-se no chamado Originalismo Vivo ou Constitucionalismo Democrático e procura rever posições clássicas do já conhecido debate entre os Originalistas e Não-originalistas no contexto da interpretação constitucional norte-americana.

PALAVRAS CHAVES: Interpretação Constitucional. Constitucionalismo Democrático. Originalismo Vivo.

\section{ABSTRACT}

The text presents the new doctrine of constitutional interpretation that originated at the School of Yale. This doctrine is based on the concept of so-called Living Originalism or Democratic Constitutionalism, and attempts to review classical positions of the well-known debate between Originalists and Non-originalists in the context of North American constitutional interpretation.

KEYWORDS: Constitutional Interpretation. Democratic Constitutionalism. Living Originalism.

\section{RESUMEN}

El presente texto tiene como objetivo presentar la doctrina de interpretación constitucional oriunda de la Escuela de Yale. Tal doctrina se fundamenta en el denominado Originalismo Viviente o Constitucionalismo Democrático e intenta revisar posiciones clásicas del ya conocido debate entre los originalistas y no originalistas en el contexto de la interpretación constitucional norteamericana.

1 Pós- Doutor Université de Montpellier I Professor do Programa de Pós Graduação da PUC/RJ E-mail: jribas@puc-rio.br.

2 Mestre e Doutorando em Direito pela PUC/RJ. Professor de Dir. Constitucional e Internacional das Faculdades Doctum de Juiz de Fora. 
PALABRAS CLAVE: Interpretación Constitucional. Constitucionalismo Democrático. Originalismo Viviente.

\section{INTRODUÇÃO}

Certa feita, ao ser perguntado qual o critério para a escolha de seus indicados à Suprema Corte Americana, o presidente Richard Nixon foi taxativo: "Eu quero um homem na Suprema Corte que seja estritamente construtivista, um homem que interprete a lei e não que tente fazer a lei" ${ }^{\prime \prime}$. Nixon expressava em palavras sua vontade de ocupar a Suprema Corte Americana com uma corrente de juristas que havia se autointitulado "intérprete original" do texto constitucional americano.

Essa corrente de homens, notadamente homens de postura conservadora, faz parte de um dos grandes debates que permeia a comunidade jurídica norte-americana e que está centrado na forma de interpretação dada pelos operadores do direito a sua Constituição. ${ }^{4}$

Este conflito se dá basicamente com a constituição de duas grandes eclássicas correntes doutrinárias que possuem visões antagônicas sobre qual seria a melhor hermenêutica para o texto constitucional americano. De um lado temos o originalismo/textualismo, do outro encontramos o não originalismo 5 .

O antagonismo entre as correntes de interpretativistas norte-americanas se dá fundamentalmente nas diferenças entre os originalistas, que veem como possível a identificação do sentido original e verdadeiro do texto constitucional, encontrando a vontade fundante que levou o legislador (founding fathers) a construir determinada norma constitucional ${ }^{6}$ ao posto que, para os não originalistas, essa norma deve ser entendida de uma maneira contextualizada e, portanto, interpretada de acordo com a contemporaniedade do tempo de sua aplicação, qual seja, com as adaptações cabíveis no momento de sua aplicação. ${ }^{7}$

Esse debate polarizou durante muito tempo o ambiente jurídico acadêmico norte-americano que, nos últimos anos, foi surpreendido com uma nova forma de interpretar a constituição do Estado. Nessa nova forma, os conceitos de interpretação original ou não tiveram seu sentido modificado, inaugurando assim uma nova corrente doutrinária. Esse novo momento inaugura o chamado Constitucionalismo Democrático ou Originalismo Vivo e obriga a comunidade americana a rever diversos debates já travados, além de impor novas questões. O desacordo está mais vivo do que nunca.

O objetivo deste artigo não é, evidentemente, exaurir todo o debate interpretativista norteamericano, tampouco entregar ao leitor uma visão pormenorizada das correntes doutrinárias adotadas em solo americano, mas tão-somente oferecer ao leitor um painel das diversas maneiras com que a academia norte-americana adota a leitura do seu texto magno, com especial destaque à corrente por nós intitulada de Escola de Yale ou Escola do Constitucionalismo Democrático Norte-Americano.

\section{ORIGINALISMO ${ }^{8}$}

Para os originalistas, a busca pelo sentido correto da constituição requer uma série de mecanismos. Quando não contemplados com uma afirmação normativa literal no texto constitucional em que possam fundamentar suas decisões, os originalistas recorrem a uma série de recursos como a história, a linguística e a antropologia. ${ }^{9}$ Esses mecanismos evitariam uma mudança na interpretação

3 "I want men on the Supreme Court who are strict constructionist, men that interpret the law and don 't try to make the law" In: KECK, Thomas M. The most activist supreme court in history: the road to modern judicial conservatism. Chicago: University Chicago Press, 2004. p. 107.

4 Para mais detalhes ver: BOBBITT, Phillip. Oxford: Blackwell Pub, 1991.

5 Os termos utilizados no presente texto seguem a tradição jurídica norte-americana. São diversas as traduções já realizadas por autores pátrios ao tratar dos termos.

6 SCALIA, Antonin. Originalism: the Lesser Evil, 57 u. cin. L.Rev. 849, 862-64.

7 STRAUSS, David A. The living constitution. New York: Oxford, 2010

8 SOLUM, Lawrence B. What is Originalism? The Evolution of Contemporary Originalist Theory. Disponível em: http://ssrn.com/abstract $=1825543$ or doi: $10.2139 /$ ssrn. 1825543.

9 BUENO, R. Intepretação constitucional: a polêmica entre o originalismo e o não-originalismo. Revista 
dos textos constitucionais e somente poderiam ser alterados de acordo com as previsões já nomeadas no artigo catorze do texto constitucional, qual seja, por meio das emendas formais. ${ }^{10}$

A constituição norte-americana é conhecida pela sua síntese e tem como um dos pontos característicos a grande dificuldade de ser alterada devido à rigidez do seu artigo quatorze. Quando o texto trata de assuntos como a idade mínima para que o cidadão possa se tornar presidente da república ou o número de senadores para cada estado, não há no que se falar em conflito de interpretação. O texto, por si só, soluciona a questão para o leitor/intérprete. A grande questão surge quando o texto constitucional não apresenta a clareza necessária para que mais de uma forma de interpretação seja possível. Emendas, como a primeira, por exemplo, trazem textos que podem ser claramente motivo de divergência entre seus leitores. O que se entende por liberdade de expressão? Tranquilamente podemos dizer que, mesmo tendo uma breve noção de que a primeira emenda protege o conceito de liberdade de expressão, este pode ser entendido das mais diversas formas, umas mais restritivas, outras não.

Segundo Balkin, há três tipos de normas dentro do texto constitucional norte-americano. A primeira delas é chamada de lei (rule) que propõe determinadas normativas específicas, como os exemplos já citados acima da idade presidencial, data de eleição, número de deputados, etc. Outra normativa adotada pela Constituição estadunidense é os chamado parâmetro (standards) como, por exemplo, o direito garantido pelo texto de que o cidadão terá um julgamento "rápido". Já os princípios (principles) garantem a liberdade de expressão ou a igualdade de proteção (equal protection). Para o autor, a grande função dessas três normativas está na razão de sua aplicação.

Diz Balkin:

São utilizadas normas fixas quando os existe a vontade de limitar-se a discricionariedade; são utilizados parâmetros ou os princípios quando existe a vontade de construir canais políticos através de certos conceitos chaves, que, por sua vez, delegam os detalhes as futuras gerações. Quando a constituição usa princípios abstratos como "liberdade de expressão" ou "igualdade de proteção", nós devemos aplicá-los de acordo com as circunstâncias de nosso tempo. ${ }^{11}$

É nessa zona cinzenta entre o entendimento de conceitos indeterminados contidos no texto constitucional americano que os originalistas pregam a necessidade de se entregar o sentido adotado pelas pessoas que assinaram o texto constitucional. ${ }^{12}$ Para esses juristas, é "inadmissível - na verdade um tipo de trapaça - utilizar as palavras da Constituição e dar a essas palavras um sentido que seja diferente daquele entendido pelas pessoas que foram responsáveis, num primeiro momento, por incluir este mesmo texto na Constituição."13

Segundo Strauss, há duas formas de originalismo. Uma delas se confundiria com a corrente chamada de constituição viva. Esta corrente afirma que o que vincula não é necessariamente o específico sentido do texto original, mas sim os princípios que atuam como autores ou retificadores da Constituição no momento de seu entendimento"14. Para essa corrente, os intérpretes estariam obrigados a seguir o sentido original, mas não necessariamente a aplicação original. ${ }^{15}$

Eletrônica da Faculdade de Direito da PUC-SP - Disponível em: http://revistas.pucsp.br/index.php/ red/article/view/2803/3958. Acesso em: 11 Nov. 2011.

10 STRAUSS, David A. The living constitution. New York: Oxford, 2010. p.4

11 "Adopters use fixed rules because they want to limit discretion; they use standards or principles because they want to channel politics through certain keys concepts but delegate the details to future generations. When the Constitution uses abstracts principles like freedom of speech or equal protection, we must apply them to our circunstances in our own time BALKIN, Jack. Fidelity to text and principle. In: BALKIN, Jack; SIEGEL, Reva. (Org). Constitution in 2020. New York: Oxford, 2010. p. 12

12 "The core ideia of originalism is that when we give meanings that the people who adopted those constitutional provisions would have assigned" STRAUSS, David A. The living constitution. p.10.

13 "impermissible - its a kind of cheating, really - to take the words of the Constitution and give those words a meaning that differs from the understandings of the people who were responsible for including those words in the constitution in the first place Strauss, David A. The living constitution, 2010, p.10.

14 STRAUSS, David A. The living constitution, 2010 p. 26.

15 SMITH, Peter J. How Different are Originalism and Non-Originalism? Hastings Law Journal, Vol. 62, 2011; GWU Law School Public Law Research Paper No. 517. Available at SSRN: http://ssrn.com/ abstract $=1702874$ Segundo o autor "This early originalism, which Keith Whittington has called the "old originalism," was largely a negative and reactive theory, concerned principally with offering a critique 
A outra forma de originalismo é aquela em que, usando os exemplos de Strauss, considera ainda hoje como penas não cruéis aquelas adotadas no momento em que a emenda que trata do assunto - a oitava - foi produzida, ou seja, em 1791. Portanto, para essa corrente de pensadores, a pena de morte pode, ainda hoje, ser considerada plenamente constitucional. Se ela não violava a constituição federal norte-americana, em 1791 ela não irá desrespeitar o texto nem hoje, nem nunca. ${ }^{16}$

Alguns pontos podem ser criticados na postura originalista de interpretação constitucional. 0 primeiro deles, e talvez o principal dos problemas, seja a impossibilidade de conseguir identificar qual o entendimento dos pais fundadores no momento da concepção da norma. A complexa identificação do sentido original do texto é uma tarefa que talvez fosse pacificamente realizada por historiadores, mas entregá-la a juízes e advogados e esperar que esses profissionais sejam capazes de realizar essa função com presteza e sem risco de equívocos é trazer uma indefinição para justamente uma das funções entregues à lei: garantir a segurança jurídica.

Além da grande probabilidade de erro na interpretação histórica do texto legal, há uma real possibilidade de a interpretação ser feita pelo magistrado da forma com que ele pessoalmente gostaria de entender o texto, e não da maneira juridicamente correta. A possibilidade de manipulação do sentido histórico do texto constitucional é um perigo que não pode deixar de ser observado.

Outro ponto levantado pelos críticos é a impossibilidade de que, mesmo identificando o sentido original do texto constitucional, outra dificuldade virá à tona. Como enquadrar esse sentido no mundo atual? É claro que o texto constitucional foi escrito tomando como parâmetro a realidade vivida por seus autores. Essa realidade hoje não pode ser mais entendida da mesma forma e uma das grandes dificuldades estaria justamente em adaptar esse entendimento descontextualizado de uma maneira que se encaixe com nossos dias.

O problema do sentido atual do texto, relatado acima, parte da necessidade de se entender que a construção do texto constitucional norte-americano foi realizada dentro da realidade de uma sociedade pequena, relativamente homogênea, predominantemente rural e, por exemplo, com armas primitivas e mobilidade limitada. Strauss pergunta se há como o intérprete identificar qual seria a postura dos autores do texto constitucional nos dias de hoje. Seria implausível imaginar que os founding fathers, chocados com as chacinas dentro de escolas por toda parte dos EUA, não sentissem necessidade de criar um regime de armas mais restrito dentro do país? Não se sabe. E é justamente por isso que, diante de novas circunstâncias sociais, novas realidades de mundo, afirmar que o entendimento dos autores seriam $X, Y$ ou $Z$ é nada mais nada menos que realizar um mero exercício de suposição. ${ }^{17}$

Um terceiro problema elencado pela doutrina crítica seria como entender a necessidade de seguir decisões tomadas há séculos, por pessoas que não vivem mais, como aquelas que seriam as corretas nos dias de hoje. Trata-se de um esforço implausível, quiçá improvável, que a população norte-americana deveria fazer. Para os críticos faltaria legitimidade. ${ }^{18}$ É o problema Jefersoniano.

A necessidade de que uma geração não se veja pautada pela agenda da geração passada era uma das preocupações de Thomas Jefferson, ao escrever para James Madinson em 1789. Para Jefferson,

of existing practice.To be sure, the early originalists labored to advance an affirmative justification for their approach as well. Bork and Berger, for example, argued that originalism was the only neutral and objective approach to interpretation and thus, the only approach that was consistent with the judicial role in a democratic society. But to its early adherents, originalism was appealing principally as a form of criticism, and primarily in contrast to what it was not Originalism has evolved a great deal since the early 1970s. As Tom Colby and others have recently explained, whereas the early proponents of originalism focused on the original intent of the Framers, many originalists eventually concluded that the proper object of inquiry was the original meaning". Para uma nova Teoria contrária a essa divisão entre entendimento do sentido original e a intenção original ver: McGINNIS, John O.; RAPPAPORT, Michael B. Original Methods Originalism: A New Theory of Interpretation and the Case Against Construction (May 19, 2009). Northwestern University Law Review, Vol. 103, No. 2, 2009. Available at SSRN: http://ssrn.com/abstract=1407274. Para a corrente do Originalismo dito Semântico ver: SOLUM, Lawrence B. Semantic Originalism. Illinois Public Law Research Paper No. 07-24. Available at SSRN: http://ssrn.com/abstract $=1120244$.

16 STRAUSS, David A. The living constitution. p.10

17 STRAUSS, David A. The living constitution. p.22

18 STRAUSS, David A. The living constitution. p.18 
uma geração tem a obrigação natural de superar a outra atuando com independência. ${ }^{19}$ Como resultado esperar que a atual geração americana identifique-se com a geração dos pais fundadores é esquecer que os próprios não só acreditam nas novas formas de pensar das gerações futuras, mas contavam com elas para concretizar um projeto que pode ser chamado de "multigeracional", como afirma de Strauss. Para o autor é necessária a determinação da natureza do projeto multigeracional para que, com isso, sejam feitas as adaptações necessárias ao nosso tempo.

Um dos grandes desconfortos causados pela interpretação originalista é a suposta utilização dessa sua postura interpretativista para justificar uma posição conservadora adotada pela Suprema Corte Americana nos últimos anos 30 anos. Tal postura fundamenta-se na liderança intelectual de Antonin Scalia que, repetidas vezes, afirma interpretar o texto constitucional da forma originalista ${ }^{20}$.

O movimento conservador que Erwin Chemerinsky chama de "Assalto à Constituição"21 tem suas bases na década de 70 com a chegada de Reagan à Presidência da República. Posteriormente, beneficiado por um momento histórico em que quatro vagas na Suprema Corte ficaram abertas dentro do seu período como presidente, Nixon indicou os Juízes Warren Burger, Harry Blackmun, Lewis Powel e William Rehnquist. ${ }^{22}$ Apesar de observarmos, com o passar do tempo, uma tendência progressista em Blackmun e mais moderada em Powell, o efeito da escolha desses novos juízes se demonstrou de imediato, principalmente no campo penal. ${ }^{23}$ Esses novos juízes se alinharam no momento aos juízes conversadores da então Corte Warren. Essa guinada à direita se acentua com as indicações de mais dois presidentes republicanos, Ronald Reagan e George W. Bush, que aturam na composição e inclusão de nomes notadamente conservadores, como Sandra O'Connor, Antonin Scalia, Anthony Kennedy e Clarence Thomas. Segundo Chemerisnky, o grande golpe do segmento conservador norte-americano se deu quando o chief justice Warren Burger se retirou da corte. Reagan escolheu como seu sucessor o jurista William Rehnquist e, para a vaga no colegiado (Associate Justice), o juiz da corte federal de apelação, o ex-professor da Universidade de Chicago, Antonin Scalia.

Scalia, já naquele momento um conhecido pensador nos círculos dos juristas conversadores e que havia ocupado cargos de relevância no departamento de justiça da administração Reagan, ${ }^{24}$ vem a se tornar o grande baluarte do conservadorismo norte-americano e, durante mais de seus vinte anos na corte "Articulou uma filosofia jurídica conservadora, frequentemente em uma linguagem rebuscada que e citada pela grande impressa. Ele é um feroz oponente do direito de aborto, de todas as formas de ações afirmativas e de qualquer tentativa de separar a igreja e o Estado."25

Segundo o justice, a constituição deve ser interpretada de acordo com "com o sentido original do texto e não com a intenção dos relatores". ${ }^{26}$ Para o juiz, o sentido original do texto deve ser lido de acordo com os princípios neles contidos, entretanto esse sentido deve ser utilizado da mesma forma que eles seriam aplicados quando foram adotados. ${ }^{27}$

Essa postura originalista proporciona aos juízes conversadores adotarem sua agenda em que, na opinião de alguns estudiosos, estariam tensionadas a alterar o sentido de diversos princípios constitucionais, adotando assim uma interpretação conservadora dos mesmos. Essa agenda não seria exclusivamente adotada pelos juízes conservadores, mas também pelos governos republicanos,

19 STRAUSS, David A. The living constitution. p. 24

20 Para um panorama do pensamento de Scalia ver: PHILIPSE, Herman, Antonin Scalia's Textualism in Philosophy. Theology, and Judicial Interpretation of the Constitution. Available at SSRN: http://ssrn. com/abstract $=1083704$.

21 CHEMERINSKY, Erwin. The conservative Assault on the Constitution. New York: Simon \& Schuster, 2010.

22 CHEMERINSKY, Erwin. The conservative Assault on the Constitution. p. 17

23 CHEMERINSKY, Erwin. The conservative Assault on the Constitution. p. 17

24 CHEMERINSKY, Erwin. The conservative Assault on the Constitution,p.19

25 "Articulated a conservative judicial philosophy, often in colorful language that is quoted in the mainstream press. He is a fierce opponent of abortoin rights, all forms of affirmative action, and any attempt to separete chucrch and state" CHEMERINSKY, Erwin. The conservative Assault on the Constitution. New York: Simon \& Schuster, 2010. p.19

26 "the original meaning of the text, not that the original draftsmen intended" Michael H. $v$ Gerald D, 491 Us. 110, 141 (1989) citado por BALKIN, Jack. Fidelity to text and principle. In: BALKIN, Jack; SIEGEL, Reva (Org.). Constitution in 2020. New york: Oxford. 2010.

27 BALKIN Jack. Fidelity to text and principle. In: Balkin, Jack e Siegel, Reva (Org.). Constitution in 2020. New York: Oxford. 2010.p. 12 
desde Nixon até Bush filho. ${ }^{28}$

Essa é talvez a maior das preocupações da corrente contrária ao originalismo apregoado por autores como Scalia, a potencialização do direito como instrumento de implementação de medidas de uma corrente política ${ }^{29}$. Ao adotar a corrente originalista que entrega a uma possível vontade histórica a solução de um conceito principiológico indeterminado, estaríamos colocando, na verdade, dentro de cada conteúdo a vontade política prevalecente da maioria dominante no momento em que aquela decisão estivesse sendo tomada. A justificativa daquela decisão não seria difícil de ser feita, como muitos Justices ainda hoje fazem, já que o sentido do texto constitucional estará, na verdade, sempre aberto à interpretação da "vontade" do justice que possui a função de dizer a ideia original do texto.

São, por essas razões, entre outras, que os críticos do originalismo buscaram oferecer propostas de novas formas de se entender a interpretação constitucional, como veremos a seguir.

\section{NÃO AO ORIGINALISMO OU O NOVO ORIGINALISMO??30}

\section{A CONSTITUIÇÃO VIVA ${ }^{31}$}

Os não originalistas possuem como características principais a consciência de que uma norma não possui necessariamente um único sentido. Seria, portanto, impossível à identificação de um significado correto e único, tal qual apregoa os originalistas, para a norma constitucional no momento de sua interpretação. Isso só seria possível ao realizar uma atualização do seu conteúdo ao concretizar a norma jurídica.

Umas das correntes 32 não originalistas evoca uma "living constitution", que é entendida como "uma constituição que envolve mudanças através dos tempos, se adapta a novas circunstâncias sem ser formalmente emendada"33. Neste caso, a aceitação de que a constituição é viva justifica-se pela conscientização de que as mudanças na sociedade americana são uma constante que podem ser melhores traduzidas no mundo jurídico por meio dos precedentes que, ao mesmo tempo, possibilitariam a mudança no entendimento do texto e agiriam como uma limitação desta mudança.

As alterações do mundo fático não podem ser percebidas, argumentam os defensores da "living constitution", pelas constituições escritas e tampouco as emendas possuiriam a velocidade adequada de acompanharem essas inovações, ao contrário dos precedentes.

Os críticos dessa corrente hermenêutica alertam, por sua vez, que a apregoada necessidade de adequação da constituição aos nossos dias pode levar a uma manipulação do sentido dela de acordo com as vontades pessoais de seus aplicadores. ${ }^{34}$

28 Segundo Chemeresky "The assault on the constitution is the result of a concerted effort by conservatives o alter foundational constitutional principles. The focus needs to be not just on the courts, but also on policies developed during the presidencies of Nixon, ford, Reagan, Bush and Bush". p. 29

29 SIEGEL, Reva; POST, Robert. Originalism as a political Practice. Fordham Law. Rev. vol 75, 2007.

30 SMITH, Peter J., How Different are Originalism and Non-Originalism? Hastings Law Journal, Vol. 62, 2011; GWU Law School Public Law Research Paper No. 517. Available at SSRN: http://ssrn.com/ abstract=1702874; Keith E. Whittington, The New Originalism, 2 Geo. J.L. \& Pub. Pol'y 599, 599-610 (2004). Com críticas ao chamado novo originalismo e a living constitution ver: GRIFFIN, Stephen M. Rebooting Originalism. Tulane Public Law Research Paper No. 07-05. Ago, 2007 disponível em SSRN: http://ssrn.com/abstract=1009393 or doi:10.2139/ssrn.1009393. O autor propõe uma "Teoria Histórica de Mudança Constitucional".

31 STRAUSS, David A. The living constitution, 2010.

32 Barroso elenca outras duas correntes: a leitura moral da constituição e o pragmatismo. Ver: BARROSO, Luis Roberto. Curso de Direito Constitucional contemporâneo. São Paulo: Saraiva, 2010, p. 283.

33 STRAUSS, David A. The living constitution. p.1.

34 STRAUSS, David A. The living constitution. p. 2 


\section{O CONSTITUCIONALISMO DEMOCRÁTICO DA ESCOLA DE YALE ${ }^{35}$}

O debate entre as correntes do originalismo e não originalismo na hermenêutica constitucional norte-americana não está passível de contestações e, para seus críticos, representam na verdade lados diversos de uma mesma moeda. Para esse conjunto de autores, ${ }^{36}$ o originalismo é, na verdade, utilizado como instrumento para a realização de uma dominação ideológica conservadora na corte norte-americana. Os não originalistas, por sua vez, não foram bem-sucedidos em frear esse movimento. Numa síntese apertada, poderíamos afirmar que a cerne dos questionamentos dos críticos às teorias clássicas se resumem ao fato de que o originalismo tradicional não pode ser sustentado como teoria jurídica e é apenas utilizado como instrumento de efetivação de uma ideologia conservadora, ao passo que os não originalistas não conseguem formar uma corrente ideologicamente forte para se contrapor aos conservadores e se resumem a argumentos jurídicos para defender sua forma de interpretação. ${ }^{37}$

Como alternativa a esse dualismo até então preponderante no debate americano, propõe o chamado constitucionalismo redentivo, baseado numa interpretação redentora e restaurativa voltada para o futuro e não mais para o passado, como os originalistas pretendem ${ }^{38}$. Essa interpretação teria como característica um retorno da legitimidade constitucional, perdida quando o sistema torna-se não só injusto de forma substancial, mas também incorrigível, por meio da participação ativa da sociedade no projeto constitucional. As pessoas devem estar aptas a discutir o projeto constitucional, concordando ou discordando, denunciando ou protestando - inclusive se opondo a decisões que julgam contrárias ao texto constitucional. O importante é colocar em prática o projeto de uma Constituição. ${ }^{39} \mathrm{~A}$ constituição seria, portanto, um trabalho em constante desenvolvimento. ${ }^{40} \mathrm{E}$ é justamente esse trabalho contínuo e em conjunto que traria a legitimação democrática do texto.

Entretanto essa chamada fé no processo de construção constitucional traz consigo, tal qual uma externalidade negativa, a possibilidade do surgimento da chamada idolatria constitucional. Essa idolatria atuaria de forma a confundir e distrair o operador, causando o afastamento dos verdadeiros objetivos do texto. ${ }^{41}$

Três podem ser as formas de idolatria constitucional. A primeira delas é aquela que esquece que a constituição é um texto imperfeito, feito e administrado por indivíduos que, como ser humano, são passíveis de falhas. Determinar que o texto constitucional é um texto sem erros e o "produto mais fino da civilização humana" é esquecer que o criador do texto é falível. O segundo engano que pode levar à idolatria constitucional é estabelecer uma discussão que não é jurídica, mas sim moral, em torno do texto constitucional. Confundir o que é justo com o que é constitucional pode impedir os analistas do texto em pensar em reformas e atualização. Uma terceira forma de idolatria constitucional é a complacência e a conformidade com as crenças morais atuais. Assumir que um sistema constitucional é o melhor justamente por ser o nosso sistema nos impede de analisar suas possíveis deficiências. ${ }^{42}$

Diante disso o papel da opinião pública torna-se fundamental. É a opinião pública que irá expressar a vontade comum dos sentidos possíveis do texto constitucional. É na sociedade que encontraremos a legitimidade do texto. Juntamente com a opinião pública surge o papel dos movimentos sociais que atuariam como instrumentos de expansão das fronteiras do razoável numa determinada época. Exigindo mudanças, novos debates e a inclusão de novos atores sociais, os movimentos sociais abrem espaço para novas formas de "imaginação constitucional e novas formas 35 POST, Robert; SIEGEL, Reva B., Roe Rage: Democratic Constitutionalism and Backlash. Harvard Civil Rights-Civil Liberties Law Review, 2007. Disponível em: http://ssrn.com/abstract=990968.

36 Liderados atualmente por uma equipe de professores da Universidade de Yale onde destacamos os professores Jack Balkin e Reva Siegel

37 POST, Robert; SIEGEL, Reva. Originalism as a political practice: the rights living constitution. Fordham Law Review, 75: 545, 2006. Ver também: Barroso, Luis Roberto. Curso de Direito Constitucional Contemporâneo, 2010, p. 282.

38 BALKIN, Jack. Constitutional Redemption. Cambridge: Harvard University Press. 2011.

39 BALKIN, Jack. Constitutional Redemption, p.10

40 BALKIN, Jack; SIEGEL, Reva (Org.). Constitution in 2020. New York: Oxford. 2010. p. 2

41 Segundo Balkin, "The constitution idolatry is the confusion of a morally compromised Constitution with justice and good government". BALKIN, Jack. Constitutional Redemption, p. 11

42 BALKIN, Jack. Constitutional Redemption, p.11 
de utopia constitucional para o bem ou para o mal". Esse papel é importantíssimo e legitima ainda mais as escolhas sociais que irão, ao cabo, entregar legitimidade plena ao texto. ${ }^{43}$

Partindo da ideia de que a carta constitucional é um texto que também possui um sentido político, a ideia da redenção constitucional procura valorizar uma nova forma de entender o texto constitucional, realizando não só uma interpretação dita jurídica, mas identificando uma interpretação que, além de aceitar o papel político da carta constitucional, utiliza-se justamente dessa dimensão do texto para colocar em prática sua forma de entender quais os melhores caminhos para o Estado. ${ }^{44}$

Segundo Balkin a:

(...) interpretação constitucional requer fidelidade ao sentido original da Constituição e aos princípios estabelecidos pelo texto ou que subjazem o texto. Uma interpretação constitucional também requer construção - decidindo como melhor executar e aplicar o texto e os princípios constitucionais em circunstâncias atuais. ${ }^{45}$

O autor chama esse método de interpretação de "Text and principle". Para ele, esse seria um método que aliaria o sentido original da constituição com seus propósitos subjacentes.

Cada geração, segue Balkin, é responsável por implementar as garantias constitucionais em seu próprio tempo, seja por meio de instituições políticas, seja por meio de uma construção legislativa, seja por meio da criação dos precedentes. O que o modelo do text and prinicple pretende é ultrapassar a ideia conservadora do termo originalista, que o autor chama de "Original Expected Application"46.

O novo modelo acredita que os membros de cada geração de americanos podem persuadir-se na tentativa de determinar como os princípios constitucionais devem ser aplicados diante das novas circunstâncias dos tempos atuais. Como as condições estão sempre mudando, novos problemas estão surgindo e novas formas de conflitos sociais emergem com isso. Assim, o processo de argumento e de persuasão sobre os sentidos dos princípios constitucionais não acabará nunca.

O sentido da Constituição será, portanto, determinado por cada geração presente. É o sentido atual que importa. Essa determinação irá, com isso, conectar os valores e os compromissos do passado e poderá seguir em frente com o projeto constitucional americano rumo ao futuro. ${ }^{47}$ Esse diálogo entre as decisões do passado, as necessidades do presente e a expectativa do futuro constitucional americano não impede que críticas sejam feitas e fomenta uma constante análise dos

43 Segundo Balkin, os movimentos sociais "Chang the sense of what is pratically possible and the sense og what it is possible to imagine." Balkin, Jack. Constitutional Redemption. Cambridge: Harvard University Press, 2011,p.11

44 Para Keith Wittiington "the constitution penetrates politics, shaping it from the inside and altering the outcomes. Along the way, the Constitution is also made subject to politics" O mecanismo que elaboraria um sentido em seu âmbito político é chamado pelo autor de "constitutional construction." Segundo o autor, "constitutional construction is one mechanism by which constitutional meaning is elaborated. Ele não poderia ser confundido com a interpretação constitucional. Para o autor" Both interpretation and construction assume a fidelity to the existing text. Both seek to elaborate a meaning somehow already present in the text, making constitutional more explicit without altering the terms of the text itself. As such, both methods of constitutional elaboration are subordinate to the text, which is understood as prior and more fundamental" A diferença entre os dois métodos, para Whittington, centra-se na característica da Construction em considerar os princípios políticos fundamentais, as futuras estruturas políticas, em ocorrer em momentos onde o entendimento do texto é incerto, em desenvolver-se em novos insterstícios na descoberta do sentido do texto e em providenciar novos standarts de conduta política. Whittington, Keith E. Constitutional Construction: divided powers and constitutional meaning. Cambridge: Havard University Press.2001. p.1-5.

45 Constitutional interpretation requires fidelity to the original meaning of the Constitution and to the principles stated by the text or that underlie the text. Constitutional interpretation also requires construction - deciding how best to implement and apply the constitutional text and principles in current circumstance BALKIN, Jack. Fidelity to Text and Principle. In: BALKIN, Jack; SIEGEL, Reva. (Org). Constitution in 2020. p.11

46 Segundo Balkin, "Original expected application asks how people living at the time the text was adopted would have expected it would be applied using language in its ordinary sense(along with any legal terms of art" p. 13

47 BALKIN, Jack. Fidelity to Text and Principle Constitution in 2020. 2010 p.16 
sentidos dos princípios contidos no texto constitucional. Caberá à geração atual analisar, refletir e julgar as interpretações da geração anterior. ${ }^{48}$

Um ponto importante nesse novo modelo de interpretação é a participação de atores que não são oriundos das cortes, como os cidadãos. Segundo Balkin, muitas das grandes mudanças de sentido do texto constitucional ocorreram não só por meio da construção de funcionários do executivo ou dos legisladores (não só no nível nacional, mas regional e local inclusive) que elaboraram instituições, programas e práticas que renovam o sentido constitucional. Elas foram, principalmente, renovadas

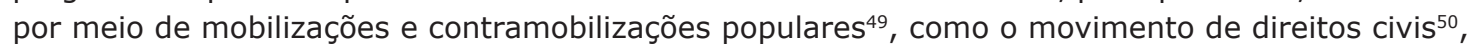
a segunda onda do feminismo americano, o New Deal, que oferece alternativas de sentido à interpretação do texto até então vigente. ${ }^{51}$

Essa mobilização possui força, inclusive, para restaurar sentidos que não estariam mais sendo utilizados. Possuem, portanto, a capacidade de redenção destes sentidos. Para o autor:

(...) os sentidos constitucionais mudam quando questionamos sobre o que nós realmente acreditamos, o que efetivamente mudamos ao fazermos essa pergunta são quais as foram as nossas promessas como povo, o que deve ser repensado e quais compromissos devem serem mantidos. ${ }^{52}$

Para a interpretação, por meio do text and principle, é a perspectiva do cidadão que deve ser privilegiada. O constrangimento dos juízes em uma democracia é importante e é esse o papel da população, seja por meio da opinião pública, seja por meio dos movimentos sociais. Construir uma teoria da interpretação que possibilite esse constrangimento, normalmente reservado a características institucionais ou políticas do sistema, permite a possibilidade jurídica deste constrangimento. A Corte constitucional, segundo a teoria do text and principle, é uma corte majoritária ${ }^{53}$ que faz parte de uma coalizão nacional e, por isso, não pode ficar distanciada dessa coalização. ${ }^{54}$

O papel central da interpretação constitucional seria realizar a confluência entre os comprometimentos das gerações do passado e das gerações do presente, aplicando o texto constitucional e seus princípios nas circunstâncias do presente, fazendo valer a legitimação da sociedade ao principal texto jurídico americano.

Essa nova forma de entender a interpretação constitucional coaduna-se com a visão do "living constitution," quando afirma que o originalismo praticado pela suprema corte americana, assaltado pelo conservadorismo que marca toda segunda metade dos anos 90 em diante, ${ }^{55}$ acaba sendo um

48 BALKIN, Jack. Fidelity to Text and Principle Constitution in 2020. 2010 p.17

49 Diz o autor "If the movements are successful, they change the minds of general public, politicians, and courts. This influence eventually gets reflected in new laws, new constitutional doctrines, and new constitutional constructions by the judiciary and political branches. Successful social and political mobilization changes political culture, which, in turn, changes constitutional practices outsides of courts and constitutional doctrine within them" p. 21 Ver também: BALKIN, Jack M. How Social Movements Change (or Fail to Change) the Constitution: the Case of the New Departure. Suffolk Law Review, Vol. 39, No. 27, 2005; Yale Law School, Public Law Working Paper No. 112. Disponível em: http://ssrn. com/abstract $=847164$.

50 Sobre o movimento de direitos civis americanos e as Cortes, relata Balkin e Reva Siegel "As social protest delegitimates certain practices, courts are often moved, consciously or unconsciously, by perceptions of status harm, to find violations of the anticlassification principle where they saw none before. Considered from this historical vantage point, American civil rights jurisprudence vindicates both anticlassification and antisubordination commitments" Ver: BALKIN, Jack M.; SIEGEL, Reva B. The American Civil Rights Tradition: Anticlassification or Antisubordination? Issues in Legal Scholarship, The Origins and Fate of Antisubordination Theory: A Symposium on Owen Fiss's Groups and the Equal Protection Clause, Vol. 2, 2002. Disponível em: http://ssrn.com/abstract $=380800$.

51 BALKIN, Jack. Constitution in 2020. 2010 p.21

52 Constitutional meaning changes by arguing about what we already believe, what we are already changes by arguing about what we have promised ourselves as a people, what we must return to, and what commitments remain to the fulfilled BALKIN, Jack.). Constitution in 2020. 2010 p.16

53 Para mais detalhes da Teoria do papel Majoritarismo da Corte Suprema Americana Ver: DAHI, Robert A. Decision-Making in a democracy: the Supreme Court as a national policy Maker. In: mimeo. Role of the Supreme Court Symposium $n^{\circ} 1$.

54 BALKIN, Jack. Constitution in 2020. 2010 p. 23.

55 Para detalhes do processo de apossamento da Suprema Corte Americana por parte dos conversado- 
instrumento político para a prática de injustiças em nome do passado. ${ }^{56}$

Entretanto não deixam de admitir que diversas técnicas adotadas pelos conservadores e expressas pelo originalismo foram bem-sucedidas e merecem atenção por parte da nova doutrina.

A interpretação constitucional adotada por Balkin coaduna-se também com o chamado Constitucionalismo Democrático da Escola de Yale. Segundo Siegel e Post, o termo é utilizado para expressar o paradoxo de que a autoridade constitucional depende da receptividade democrática e da legitimidade da lei. ${ }^{57}$

O constitucionalismo democrático seria uma nova forma de abordagem que busca superar a preponderância do modelo originalista, ao aliar uma teoria preocupada com a mobilização popular, com as diferenças culturais ${ }^{58}$, com uma participação da sociedade civil na qual os compromissos progressistas possam ser expressos por meio da lei, utilizando os "founding fathers" sem, entretanto, desautorizar novas formas de autoridade constitucional. Trata-se de uma abordagem inovadora que marca um novo momento no debate norte-americano, em que a reação liberal procura aliar argumentos jurídicos e políticos para se contrapor de forma eficaz à interpretação conservadora que atualmente prepondera na suprema corte americana.

Para os teóricos do Constitucionalismo Democrático, a constituição possui muitas funções. A primeira delas seria estabelecer as regras do jogo e são claras. Entretanto existem outras provisões constitucionais que expressam normas mais amplas ou standards ${ }^{59}$. São por serem justamente abertas em seu sentido que as normas standards geram intenso debate político. São esses debates que, apesar de à primeira vista poderem ameaçar a legitimidade da Constituição, vão levar a uma maior autoridade ao texto constitucional ${ }^{60}$ Entretanto, se as decisões da Corte Suprema não coadunarem com o sentido entendido pela população nos assuntos mais caros ao povo a Constituição, corre o risco de não ser mais reconhecida como pertencente a esse povo, tornando-se, assim, ilegítima. Para os autores do Constitucionalismo Democrátic,o a legitimidade da Constituição é dependente da relação de reconhecimento do texto com o povo. ${ }^{61}$

A crença na Constituição, em seu papel dentro do Estado, sua importância, permite aos indivíduos que, mesmo sendo tomadas decisões contrárias à sua opinião sobre determinado assunto, confiem no texto constitucional. Essa confiança só é possível se o Estado permitir que um constante debate sobre o sentido/significado do texto seja produzido pela sociedade. É a possibilidade de desacordo que, dizem os autores, leva à preservação da autoridade constitucional.

Essa consciência da importância do debate sobre o sentido atual do texto jurídico/político é que irá dar legitimidade a esse mesmo texto. Quando a corte interpreta a constituição de forma desconectada com esse debate, ela transforma o texto em ilegítimo e opressivo e pode causar com isso uma ruptura entre a população e sua crença com a autoridade do texto vigente. E é aí que surge o perigo.

Nasce, então, a pergunta: como pode a constituição permanecer como lei fundamental, como limite e fundamento da política e ainda assim permanecer democraticamente responsável? Para a Escola de Yale, se, por um lado os EUA possuem em sua constituição mecanismos clássicos, com o artigo cinco, outros mecanismos são necessários como as escolhas dos juízes da Suprema Corte pelos presidentes da República e as pressões populares contestando interpretações de normas. ${ }^{62}$

res, Ver: The conservative assualt of constitution de Erwin Chemerisky. New York: Simon \& Shuster, 2010.

56 BALKIN, Jack; SIEGEL, Reva (Org.). Constitution in 2020. 2010 p.4

57 SIEGEL, Reva and POST, Robert. Democratic Constititionalism. In: BALKIN, Jack; SIEGEL, Reva. (Org). Constitution in 2020. New York: Oxford. 2010. p. 27.

58 POST, Robert. Democratic Constitutionalism and Cultural Heterogeneity, 2000. Australian Journal of Legal Philosophy. Disponível em: http://ssrn.com/abstract=229161.

59 É interessante ressaltar que nesse momento Reva Siegel e Robert Post se distinguem na conceituação das regras contidas da Constituição americana de Jack Balkin que, como vimos anteriormente, fundamenta sua Teoria do Text and Principles em Regras, Standards e Principles.

60 SIEGEL, Reva; POST, Robert. Democratic Constititionalism. In: BALKIN, Jack; SIEGEL, Reva (Org.). Constitution in 2020. New York: Oxford. 2010. p. 27

61 SIEGEL, Reva; POST, Robert. Constitution in 2020. 2010. p. 27.

62 SIEGEL, Reva; POST, Robert. Constitution in 2020. 2010. p. 29. 
O importante é coincidir o entendimento do texto constitucional com os valores atuais da sociedade. São esses valores que serviram de baliza e - por que não? - de enquadramento da maneira pela qual a Corte irá interpretar o texto constitucional. Quando a interpretação constitucional não é feita desta maneira, tal qual os originalistas conservadores liderados por Scalia fazem nos dias de hoje, há uma falha no sentido da Constituição. ${ }^{63}$ Esse é o atual descompasso entre a sociedade, a constituição e a instituição que a interpreta.

Para reverter essa atual conjuntura, que afasta a crença da população na constituição e com isso enfraquece sua autoridade, os autores propõe três implicações aos progressistas. A primeira delas impõe ao grupo de estudiosos e operadores contrários ao originalismo atualmente reinante um método de interpretação progressista ${ }^{64}$ que consiga articular uma visão convincente de suas posições e que seja capaz de mobilizar a opinião pública do país. Trata-se, realmente, de uma proposta com o objetivo de se criar uma teoria de interpretação constitucional mobilizadora.

A segunda implicação consiste em transmutar os compromissos progressistas em lei. Somente assim os progressistas conseguirão a autoridade necessária para empoderar juridicamente os cidadãos que concordam com sua visão constitucional, dando-lhes subsídios jurídicos para a mobilização em torno da exigência da mudança de atitude dos poderes executivos e judiciários. Uma terceira proposta sugere que a doutrina interpretativista possa recorrer aos pais fundadores no momento da sua interpretação sem, contudo, elevá-los à única fonte de autoridade sobre a visão constitucional. A grande questão para os progressistas é como sua visão de constituição pode ser mais bem convertida em efetivas demandas constitucionais. ${ }^{65}$ Todas essas propostas, finalizam os autores, devem ser realizadas sem apelar ao minimalismo que, segundo os mesmos, não conseguiria dotar seguidas gerações de americanos com a confiança da importância do seu papel no entendimento do sentido da Constituição. ${ }^{66}$

Adotando essa postura jurídica crítica, acreditam os autores, será possível reverter a história recente da interpretação constitucional e implantar uma nova forma de entender os textos, distanciando-se do conservadorismo que prepondera hoje na grande maioria dos julgamentos da Suprema Corte Americana.

O desenlace de tal movimento e a reação da academia já podem ser observados ${ }^{67}$, mas ainda é cedo para sabermos qual será o desfecho - ou se teremos um desfecho - nesse clássico debate da teoria constitucional estaduninense.

\section{CONCLUSÃO}

O principal objetivo do texto é apresentar a nova corrente doutrinária no campo da interpretação constitucional americana: a chamada Escola de Yale ou constitucionalismo Democrático. Sem ter o intuito de exaurir o tema, o texto foi dividido em dois momentos principais. Há, numa primeira etapa, a apresentação das correntes já existentes e que atuam em campos distintos dentro do debate norte-americano. Num segundo passo, identifica-se o surgimento de uma nova metodologia de interpretação do texto constitucional americano e, a partir da demarcação de suas diferenças com as propostas anteriores, o artigo se propõe a enumerar as principais características dessa nova escola jurídica, apresentando ao leitor suas mais marcantes proposições.

\section{REFERÊNCIAS}

ALEXANDER, Larry. The Method of text and? Jack Balkin's Originalism whit no regrets. Legal Studies Research Paper series. No 11- 067. 2011

63 Um ponto crítico que deve ser levantado em relação aos constitucionalistas democráticos é a não discussão da sua premissa básica de que a sociedade americana está em descompasso com as decisões conservadoras da Corte Suprema.

64 Proposta por Jack Baklin ao criar o método de Text and Principle.

65 SIEGEL, Reva and POST, Robert. Democratic Constititionalism. In: BALKIN, Jack; SIEGEL, Reva. (Org). Constitution in 2020. New York: Oxford. 2010. p. 32.

66 SIEGEL, Reva; POST, Robert. Constitution in 2020. p. 33.

67 ALEXANDER, Larry. The Method of text and? Jack Balkin's Originalism whit no regrets. Legal Studies Research Paper series. No 11- 067. 2011 
BALKIN, Jack. Constitutional Redemption. Cambridge: Harvard University Press. 2011

BALKIN, Jack; SIEGEL, Reva (Org.). Constitution in 2020. New York: Oxford. 2010

The American Civil Rights Tradition: Anticlassification or Antisubordination? Issues in Legal Scholarship, The Origins and Fate of Antisubordination Theory: A Symposium on Owen Fiss's "Groups and the Equal Protection Clause, Vol. 2, 2002. Disponível em: Available at SSRN: http://ssrn. com/abstract $=380800$. Acesso em: 06/02/2013.

BARROSO, Luis Roberto. Curso de Direito Constitucional Contemporâneo. São Paulo: Saraiva, 2010. BOBBITT, Phillip. Constitutional Interpretation. Oxford: Blackwell Pub. 2001

BUENO, R. Interpretação constitucional e Polemica entre Originalismo e Não originalismo. Revista Eletrônica da Faculdade de Direito da PUC-SP. São Paulo, Vol. 3, 2010.

CHEMERINSKY, Erwin. The conservative Assault on the Constitution. New York: Simon \& Schuster, 2010.

DAHL, Robert A. Decision-Making in a democracy: the Supreme Court as a national policy Maker. In: mimeo Role of the Supreme Court Symposium $\mathbf{n}^{\circ} \mathbf{1}$.

GRIFFING, Stephen M. Rebooting Originalism. Tulane Public Law Research Paper, No. 07-05, Agosto, 2007.

KECK, Thomas M. The most activist supreme court in history: the road to modern judicial conservatism. Chicago: University Chicago Press, 2004

McGINNIS, John O.; RAPPAPORT, Michael B. Original Methods Originalism: A New Theory of Interpretation and the Case Against Construction. Northwestern University Law Review, Vol. 103, No. 2. Maio, 2009.

PHILIPSE, Herman. Antonin Scalia's Textualism in Philosophy, Theology, and Judicial Interpretation of the Constitution. Utrecht Law Review, Utrecht, Vol. 3, No. 2, pp. 169-192. December, 2007.

POST, Robert. Democratic Constitutionalism and Cultural Heterogeneity Australian Journal of Legal Philosophy, 2000. Disponível em: SSRN: http://ssrn.com/abstract=229161. Acesso em: 06/02/2013

POST, Robert; SIEGEL, Reva. Originalism as a political practice: the rights living constitution. Fordham Law Review, vol. 75, p. 545. 2006.

Roe Rage: Democratic Constitutionalism and Backlash. Harvard Civil Rights-Civil Liberties Law Review, 2007. Disponível em: SSRN: http://ssrn.com/abstract=990968. Acesso em: 06/02/2013

SCALIA, Antonin. Originalism: the Lesser Evil. University of Cincinnati law review. vol.57, n.3 ,p.849864. 1989.

SMITH, Peter J. How Different are Originalism and Non-Originalism? Hastings Law Journal, Vol. 62. 2011.

SOLUM, Lawrence B., What is Originalism? The Evolution of Contemporary Originalist Theory. Abril, 2011.

Semantic Originalism. Illinois Public Law Research Paper No. 07-24. Novembro, 2008.

STRAUSS, David A. The living constitution. New York: Oxford, 2010.

TAVARES. Andre Ramos. Constituição é um documento Valorativo. Revista Brasileira de Direito Constitucional. No 9. p. 337 -345 Jan/Jul. 2007.

VIEIRA, Jose Ribas (Org.). Teoria Constitucional Norte Americana Contemporânea. Rio de Janeiro: Lúmen Júris, 2011.

2007.

Perspectivas da Teoria constitucional Contemporânea. Rio de Janeiro: Lúmen Júris,

WHITTINGTON, Keith E. Constitutional Construction: divided powers and constitutional meaning. Cambridge: Havard University Press, 2001.

The New Originalism, Georgetown Journal of Law \& Public Policy, Vol. 2, 2004. Disponível em: http://ssrn.com/abstract=557924. Acesso em: 06/02/2013 